\title{
Flow Boiling Heat Transfer and Two-Phase Flow of Carbon Dioxide: Fundamentals, Mechanistic Models and Applications
}

\author{
Lixin Cheng ${ }^{1,2}$ and Guodong Xia ${ }^{2}$ \\ ${ }^{1}$ Department of Engineering and Mathematics, Sheffield Hallam University \\ City Campus, Howard Street, Sheffield S1 1WB, UK \\ 1.cheng@shu.ac.uk \\ ${ }^{2}$ College of Environmental and Energy Engineering, Beijing University of Technology \\ Beijing, China \\ xgd@bjut.edu.cn
}

\begin{abstract}
In order to design evaporators for the $\mathrm{CO}_{2}$ thermal systems effectively, it is essential to understand the fundamentals and mechanisms of flow boiling heat transfer, flow patterns and two-phase flow characteristics of $\mathrm{CO}_{2}$ inside horizontal tubes including both the macro- and micro- channels. The proper prediction models for $\mathrm{CO}_{2}$ flow boiling heat transfer should be relevant to the physical mechanisms and corresponding flow patterns. This paper presents a comprehensive review of flow boiling heat transfer and two-phase flow of $\mathrm{CO}_{2}$ characteristics and their prediction methods. First, the review addresses the extensive experimental studies on flow boiling heat transfer and two-phase flow in macro-channels and micro-channels. Then, The studies of $\mathrm{CO}_{2}$ two-phase flow patterns are summarized. Furthermore, the effects of oil on the flow boiling heat transfer and two-phase pressure drops are analyzed. The generalized mechanistic models for flow boiling heat transfer and two-phase pressure drops of $\mathrm{CO}_{2}$ and a new flow pattern map specially for $\mathrm{CO}_{2}$, which cover both macro- and micro- channels developed by Cheng et al. are presented and compared to the experimental data in the literature. It has been proved that the models and flow maps favorably agree with the experimental data. In the application aspect, comparison of simulation results and the experimental data in the real thermal systems are presented.
\end{abstract}

Keywords: Carbon dioxide, flow boiling, two phase flow, flow patterns, heat transfer, flow pattern map, dryout, mechanisms, mechanistic model and applications.

\section{Introduction}

As a natural working fluid, $\mathrm{CO}_{2}(\mathrm{R} 744)$ has no ozone depletion potential (ODP $\left.=0\right)$ and a negligible direct global warming potential $(\mathrm{GWP}=1)$ when used as a refrigerant. It is also an excellent coolant which has potential applications in various engineering applications such as cooling for electronic chips and other high heat flux removal [1-8]. $\mathrm{CO}_{2}$ has a low critical temperature $\left(T_{c r}=31.1^{\circ} \mathrm{C}\right)$ and a high critical pressure $\left(p_{c r}=7.38 \mathrm{MPa}\right)$, therefore, $\mathrm{CO}_{2}$ is utilized at much higher operating pressures in air-conditioning and heat pump systems compared to other conventional refrigerants. Furthermore, $\mathrm{CO}_{2}$ has positive attributes as a secondary refrigerant at low temperatures in commercial refrigeration used in supermarkets, shops and large kitchens etc., in indirect and low temperature cascade systems and as a primary refrigerant in all $\mathrm{CO}_{2}$ centralized refrigeration systems. For example, In an ammonia- $\mathrm{CO}_{2}$ secondary loop of an indirect refrigeration system, $\mathrm{CO}_{2}$ evaporation and condensation processes are nearly at the same pressures. In particular, this system does not involve any oil effect for the $\mathrm{CO}_{2}$ secondary loop. The main benefits for using $\mathrm{CO}_{2}$ in indirect system arrangements include the simplicity of the system and the possibility of using components for other refrigerants to build the $\mathrm{CO}_{2}$ circuit. In recent years, other arrangements, such as cascade and multistage systems have been used commercially [3]. Advantages of $\mathrm{CO}_{2}$ cascade systems include greatly reduced low-temperature compressor size, the absence of a liquid pump and fewer stages of heat transfer. Furthermore, two-stage and multistage $\mathrm{CO}_{2}$ centralized refrigerant systems are also used in supermarket refrigeration. These systems are most suitable for cold climates or where heat sinks are available. The operation of such refrigeration systems is mostly in the sub-critical region. If the ambient temperature is higher than the critical temperature, the system will be supercritical and this generally should be connected to another thermal system such as hot water or space heating heat pumps for efficient energy use. Due to its excellent safety characteristics (nonflammable, non-explosive, inexpensive and relatively nontoxic), $\mathrm{CO}_{2}$ is an ideal refrigerant to be used in the refrigerated spaces. Due to the high working pressure, $\mathrm{CO}_{2}$ as a phase change secondary refrigerant has a high volumetric refrigeration capacity, which equates to approximately five times or more 
that of $\mathrm{R} 22$ and $\mathrm{NH}_{3}$. As the effects of good thermophysical properties, favorably evaporation heat transfer and two-phase flow characteristics of $\mathrm{CO}_{2}$, smaller pipe dimensions can be used in its refrigeration systems. The use of $\mathrm{CO}_{2}$ in these refrigeration systems requires the understanding and prediction of convective boiling, two-phase flow patterns and pressure drops at low temperatures for achieving more accurate designs of evaporators and more energy-efficient cycles using $\mathrm{CO}_{2}$.

Furthermore, $\mathrm{CO}_{2}$ has favorable thermal performance when used in air-conditioning and heat pump systems as compared to conventional refrigerants. For example, in the $\mathrm{CO}_{2}$ automobile air-conditioning system. for ambient air temperatures, the heat transfer process on the high pressure side of a $\mathrm{CO}_{2}$ cycle is not a condensation process as in conventional systems but a supercritical gas cooling process $[3,4,6]$. For the evaporation processes in the evaporator, $\mathrm{CO}_{2}$ evaporates at much higher pressure than conventional refrigerant $\mathrm{R} 134 \mathrm{a}[1,3]$. The physical and transport properties of $\mathrm{CO}_{2}$ are quite different from those of conventional refrigerants at the same saturation temperatures. The physical properties have a significant effect on the evaporation processes including the two-phase flow patterns, evaporation heat transfer characteristics and two-phase frictional pressure drops in the compact heat exchangers with micro-channels. Therefore, it is essential to understand the two-phase flow and evaporation processes for properly designing the evaporators which use micro-scale channels for the automobile air-conditioning and heat pump systems.

Both macro- and micro-scale channels are used in the $\mathrm{CO}_{2}$ refrigeration, air-conditioning and heat pump systems. For example, in the automobile air-conditioning systems, micro-scale channels with diameters of 0.6 to $1 \mathrm{~mm}$ are generally used in evaporators, internal heat exchangers and gas coolers while macro- and micro-channels are used for $\mathrm{CO}_{2}$ refrigeration and heat pump systems. Due to the significant differences of two-phase flow and evaporation heat transfer phenomena in microscale channels as compared to conventional size channels or macro-scale channels, emphasis has been put on the characteristics of two-phase flow and heat transfer in small and micro-scale flow passages due to the rapid development of micro-scale devices in recent years [9-15]. Experimental studies and models on $\mathrm{CO}_{2}$ flow boiling and two-phase flow characteristics have been conducted in both macro- and microchannels as well [16-33].

One very important issue should be the clarification of the distinction between micro-scale channels and macro-scale channels. However, a universal agreement is not clearly established in the literature. Instead, there are various definitions on this issue $[9,10,12,13,15]$. Here, just to show two examples, based on engineering practice and application areas such as refrigeration industry in the small tonnage units, compact evaporators employed in automotive, aerospace, air separation and cryogenic industries, cooling elements in the field of microelectronics and micro-electro-mechanical-systems (MEMS), Kandlikar [9] defined the following ranges of hydraulic diameters $D_{h}$ which are attributed to different classifications:

- Conventional channels: $D_{\mathrm{h}}>3 \mathrm{~mm}$.

- Minichannels: $D_{\mathrm{h}}=200 \mu \mathrm{m}-3 \mathrm{~mm}$.

- Microchannels: $D_{\mathrm{h}}=10 \mu \mathrm{m}-200 \mu \mathrm{m}$.

Kew and Cornwell [10] earlier proposed the Confinement number Co for the distinction of macro- and micro-scale channels, as

$$
C o=\frac{1}{D_{h}} \sqrt{\frac{4 \sigma}{g\left(\rho_{L}-\rho_{G}\right)}}
$$

which is based on the definition of the Laplace constant [15]. Other different definitions are also proposed in the reviews $[12,13,15]$. Obviously, there is no agreement on the definition of a micro-scale channel so far. Figure 1 shows the comparable definitions macro- and micro-scale channels for $\mathrm{CO}_{2}$ according to Kandlikar [9] and the Confinement number Co (Equation 1), which shows the big difference among these criteria. In this chapter, the distinction between macro- and micro-scale channels by the threshold diameter of $3 \mathrm{~mm}$ is adopted due to the lack of a well-established theory but is in line with those recommended by Kandlikar [9] and also for the practical use in the $\mathrm{CO}_{2}$ air-conditioning, heat pump and refrigeration systems. 


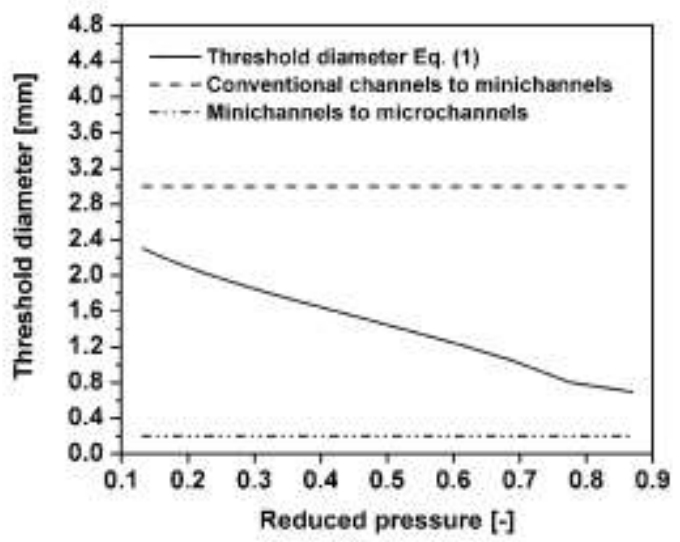

Fig. 1: Comparison of the definitions of macro- and micro-scale channels for $\mathrm{CO}_{2}$ according to Kandlikar [9] and Confinement number Co $[10]$.

From a predictive standpoint, many features of the existing flow pattern maps, evaporation heat transfer and two-phase pressure drop correlations require refinement to attain the desired level of accuracy for the design of refrigerant heat evaporators. Therefore, this review paper addresses all the issues related to $\mathrm{CO}_{2}$ two-phase flow boiling heat transfer, frictional pressure drop, flow patterns and evaporation heat transfer without and with oil effect. Emphasis is given to the $\mathrm{CO}_{2}$ two phase flow patterns, evaporation heat transfer and pressure drop models for $\mathrm{CO}_{2}$ evaporation inside horizontal tubes. The future research needs in the $\mathrm{CO}_{2}$ two-phase flow and evaporation heat transfer are identified according to the analysis of the existing studies. Some simulated results are compared to the measured performance in the real thermal systems.

\section{Analysis of Experimental Data of $\mathrm{CO}_{2}$ Evaporation inside Tubes}

Thome and Ribatski [1] presented an overall review on two-phase flow and flow boiling of $\mathrm{CO}_{2}$ in macro- and microchannels in 2005. Since then, a number of experimental and modeling work has been conducted. In particular, Cheng et al. [16-19] did comprehensive literature review on the relevant topics, collected the experimental results from different studies and critically analysed the results in developing new flow pattern map and models for evaporation heat transfer and frictional pressure drops of $\mathrm{CO}_{2}$ inside horizontal tubes. Based on the database setup, Cheng et al. [16, 18, 19] have developed a general flow pattern map covering all flow patterns, flow pattern based evaporation heat transfer and two phase frictional pressure drop models for $\mathrm{CO}_{2}$ evaporating inside horizontal models. Over the past 10 years, these prediction methods for flow patterns, heat transfer coefficients and pressure drops have been proved to be able to favourably capture the experimental data by various researchers. Here we do not do another comprehensive review but present a systematic knowledge on this topic. Behaviours of flow boiling heat transfer, two-phase flow patterns and two-phase pressure drops without oil effect are briefly summarized according to the available studies. The $\mathrm{CO}_{2}$ flow pattern map, flow pattern based flow boiling heat transfer model and phenomenological two-phase frictional pressure drop model are mainly presented.

According to the available studies in the literature, quite different evaporation heat transfer and two-phase flow behaviours of $\mathrm{CO}_{2}$ have been shown for high and low reduced pressures [16]. The evaporation heat transfer and two-phase flow characteristics of $\mathrm{CO}_{2}$ at the saturation temperatures ranging from 0 to $25^{\circ} \mathrm{C}$ show quite different characteristics as compared to those of conventional refrigerants due to the significant differences in physical properties. Generally, $\mathrm{CO}_{2}$ has much higher evaporation heat transfer and much lower pressure drops than other low-pressure refrigerants. One feature is the dominance of the nucleate boiling at low/moderate vapor qualities prior to dryout [20-24]. Another feature is that the dryout in $\mathrm{CO}_{2}$ flow boiling occurs much earlier (at relatively lower vapor qualities) than conventional refrigerants. Furthermore, the effect of the saturation temperature on the evaporation heat transfer coefficients is noticeable. At higher saturation temperatures, the nucleate boiling is more pronounced and plays an important role at the low vapor quality. 


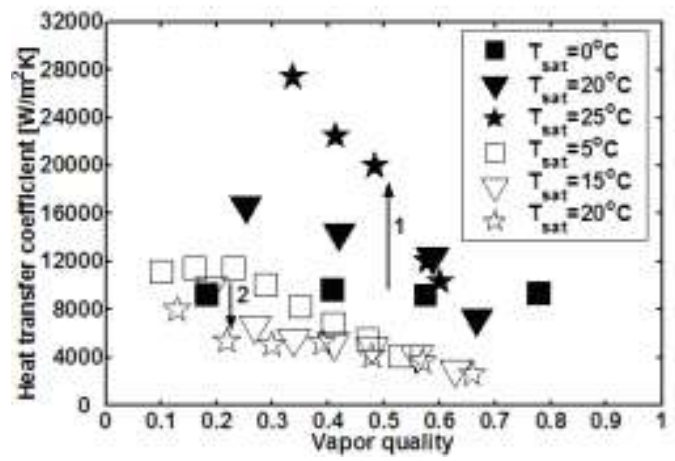

Fig. 2: The experimental heat transfer coefficients in two different studies showing two opposite trends with the increase of saturation temperature. Arrow 1 showing the trend of the experimental flow boiling heat transfer coefficients (solid symbols) of Pettersen [20]: $\mathrm{D}_{\mathrm{h}}$ $=0.8 \mathrm{~mm}, \mathrm{G}=280 \mathrm{~kg} / \mathrm{m}^{2} \mathrm{~s}$ and $\mathrm{q}=10 \mathrm{~W} / \mathrm{m}^{2}$ at 0,20 and $25^{\circ} \mathrm{C}$. Arrow 2 showing the trend of the experimental flow boiling heat transfer coefficients (hollow symbols) of Yoon et al. [24]: $\mathrm{D}_{\mathrm{h}}=7.53 \mathrm{~mm}, \mathrm{G}=318 \mathrm{~kg} / \mathrm{m}^{2} \mathrm{~s}$ and $\mathrm{q}=16.4 \mathrm{~W} / \mathrm{m}^{2}$ at 5,15 and $20{ }^{\circ} \mathrm{C}$.

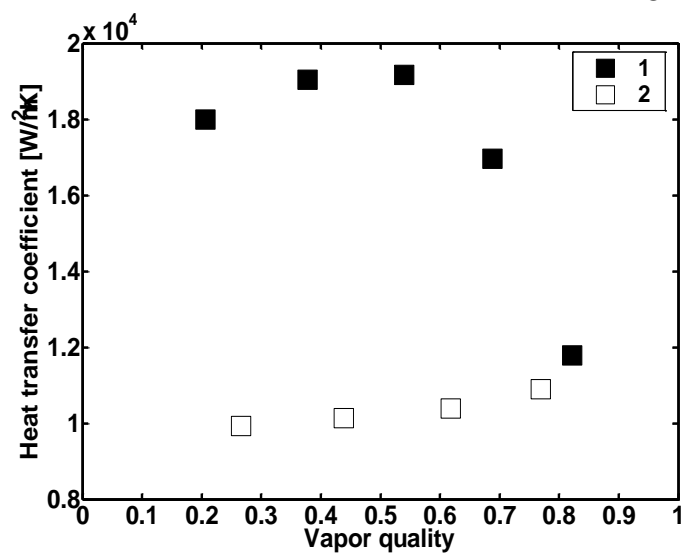

Fig. 3. The experimental flow boiling heat transfer coefficients in the same study showing different results with a very little change of hydraulic diameters from $1.53 \mathrm{~mm}$ to $1.54 \mathrm{~mm}$. Solid symbols showing the experimental flow boiling heat transfer coefficients of Yun et al. [25]: $\mathrm{D}_{\mathrm{h}}=1.53 \mathrm{~mm}, \mathrm{G}=300 \mathrm{~kg} / \mathrm{m}^{2} \mathrm{~s}, \mathrm{~T}_{\mathrm{sat}}=5^{\circ} \mathrm{C}$ and $\mathrm{q}=20 \mathrm{~W} / \mathrm{m}^{2}$. Hollow symbols showing the experimental flow boiling heat transfer coefficients of Yun et al. al. [29]: $\mathrm{D}_{\mathrm{h}}=1.54 \mathrm{~mm}, \mathrm{G}=300 \mathrm{~kg} / \mathrm{m}^{2} \mathrm{~s}, \mathrm{~T}_{\text {sat }}=5{ }^{\circ} \mathrm{C}$ and $\mathrm{q}=20 \mathrm{~W} / \mathrm{m}^{2}$.

It should be pointed out here that the experimental data from the different independent studies show somewhat quite different evaporation heat transfer trends at similar test conditions. Just to show several examples here, two opposite evaporation heat transfer behaviours with the saturation temperature are presented in the studies of Pettersen [20] and Yoon et al. [24] as shown in Fig. 2. Heat transfer coefficients increase with increasing saturation temperature in the study of Pettersen while they decrease in the study of Yoon et al. The only big difference between the two studies is the diameter of the test channels. Figure 3 shows comparison of the experimental data of Yun et al. [25] for two diameters of $1.53 \mathrm{~mm}$ and $1.54 \mathrm{~mm}$ at the same test conditions. According to their results, the evaporation heat transfer coefficients can be higher up to $80 \%$ with a very little change of hydraulic diameter from $1.53 \mathrm{~mm}$ to $1.54 \mathrm{~mm}$ at the same test conditions. No explanation why there is such a big difference even was offered in their paper. For another example, the heat transfer data of Hihara [23] at a mass velocity of $360 \mathrm{~kg} / \mathrm{m}^{2} \mathrm{~s}$, a saturation temperature of $15{ }^{\circ} \mathrm{C}$ and a heat flux of $18 \mathrm{~kW} / \mathrm{m}^{2}$ with two different tube diameters, 4 and $6 \mathrm{~mm}$. It shows that the heat transfer coefficients of the $4 \mathrm{~mm}$ tube are twice those of the $6 \mathrm{~mm}$ tube. In addition, the trends of the heat transfer coefficients are totally different. As both diameters are in the range of macro scale, it is surprising that the diameter has such a big effect on the heat transfer values and trends. Hence, in summary, there is still not a clear view of why $\mathrm{CO}_{2}$ data do not conform to conventional trends and also differ widely from one study to another.

It is difficult to explain the experimental results in some studies at low temperatures. So far, there are several studies of $\mathrm{CO}_{2}$ at low temperatures in the literature but still very limited information available. Bredensen et al. [28] performed the boiling heat transfer experiments with $\mathrm{CO}_{2}$ at temperatures of $-10^{\circ} \mathrm{C}$ and $-25^{\circ} \mathrm{C}$. The experimental results show the heat transfer coefficient increases with vapor quality until dryout, which is opposite to the trend of their data at $0^{\circ} \mathrm{C}$. Knudsen and 
Jensen [29] measured flow boiling heat transfer coefficients of $\mathrm{CO}_{2}$ in a horizontal tube of diameter $10.06 \mathrm{~mm}$ at the saturation temperatures of $-28^{\circ} \mathrm{C}$ and $-30^{\circ} \mathrm{C}$. Their boiling heat transfer coefficients are much lower than others' data. Zhao and Bansal [30] presented experimental heat transfer data at $-30^{\circ} \mathrm{C}$. Park and Hrnjak [4] showed the heat transfer coefficients in a $6.1 \mathrm{~mm}$ inner diameter tube at -30 and $-15^{\circ} \mathrm{C}$ for various mass fluxes and heat fluxes. Quite big differences among these data are found. It is difficult to explain why there are such big differences although the test conditions are similar. Considering the big differences among the available data, it is recommended that more and accurate experimental data at low temperatures are needed by careful and well designed experiments. Furthermore, empirical heat transfer methods do not capture the parametric trends in dryout and mist flow regimes and cannot explain the physical mechanisms although they predict some data well in some cases. Therefore, an improved heat transfer model based on flow regimes for flow boiling is needed, but first accurate experimental data under wide test conditions are needed. Regarding the flow boiling heat transfer mechanisms, high reduced pressures and low surface tensions for $\mathrm{CO}_{2}$ compared to conventional refrigerants have major effects on nucleate boiling heat transfer characteristics. Previous studies have suggested a clear dominance of nucleate boiling heat transfer even at very high mass flux. Therefore, $\mathrm{CO}_{2}$ has much higher heat transfer coefficients than those of conventional refrigerants at the same saturation temperature and the available heat transfer correlations generally underpredict the experimental data of $\mathrm{CO}_{2}$. In addition, previous experimental studies have demonstrated that dryout trends occur earlier at moderate vapor qualities in $\mathrm{CO}_{2}$, particularly at high mass flux and high temperature conditions. However, it is difficult to explain the available boiling data at low temperatures according to these mechanisms although nearly all these studies pointed to nucleate boiling dominant mechanism with respect to their data. From the physical properties at low temperatures, it seems that these heat transfer behaviours should be similar to those at high saturation temperatures but they are not indeed. Thus, understanding of the two-phase flow and heat transfer characteristics of $\mathrm{CO}_{2}$ at low temperatures is essential. Furthermore, for flow boiling in enhanced tubes, Koyama et al. [32] conducted experiments on flow boiling in a smooth copper tube and in a micro-fin copper tube at $5.3^{\circ} \mathrm{C}$. From their results, the heat transfer coefficients are only slightly higher than in the microfin tubes with a slight pressure drop increase as well. In this case, microfin tubes are not appropriate for $\mathrm{CO}_{2}$. Cho and $\mathrm{Kim}$ [33] conducted experimental studies of $\mathrm{CO}_{2}$ for micro-channels and their data show that the average evaporation heat transfer coefficients ware 150 to $210 \%$ higher than those of smooth tubes. The increase of pressure drop was much lower than the heat transfer increase. So far, only limited studies of $\mathrm{CO}_{2}$ flow boiling in micro-fin tubes are available. Whether they significantly enhance $\mathrm{CO}_{2}$ flow boiling heat transfer or not is still unclear due to the lack of such information.

According to then overall review of evaporation heat transfer and two-phase flow of $\mathrm{CO}_{2}$ by Thome and Ribatski [4], none of the available prediction methods was able to predict the experimental data of $\mathrm{CO}_{2}$ well. Therefore, they suggested that a new evaporation heat transfer prediction method should be developed and the evaporation heat transfer model should include the $\mathrm{CO}_{2}$ effects on the annular to dryout and dryout to mist flow transitions in order to more accurately predict heat transfer coefficients at moderate/high vapor qualities. In response, Cheng et al. $[16,17]$ proposed a new flow pattern map and a new evaporation heat transfer model based on the flow patterns for $\mathrm{CO}_{2}$ evaporating inside horizontal tubes. The flow map and flow pattern based mechanistic heat transfer model were developed by modifying the methods of Wojtan et al. [34, 35], which is an updated version of the Kattan-Thome-Favrat [36-38] flow pattern map and evaporation heat transfer model which were developed for five conventional refrigerants. The Cheng et al. related the flow patterns to the corresponding evaporation heat transfer mechanisms for $\mathrm{CO}_{2}$, thus, different from the numerous empirical models, such as the correlations of Chen [40], which do not include flow pattern information. In fact, some of these correlations predicted the data well to some extent but fail to capture the parametric trends, or ignore the dryout and mist flow regimes which are typical working conditions for $\mathrm{CO}_{2}$ evaporating in horizontal channels. The model reasonably predicts the database and it covers channel diameters found in most $\mathrm{CO}_{2}$ evaporation applications. However, their model is limited by its parameter ranges from being applicable to some important applications, for example, the mass velocity ranges from 50 to $1500 \mathrm{~kg} / \mathrm{m}^{2} \mathrm{~s}$ in $\mathrm{CO}_{2}$ automobile air conditioning systems and other thermal systems. In addition, the heat fluxes in some applications go beyond the maximum value in the Cheng-et al. evaporation heat transfer model. Furthermore, the model does not extrapolate well to these conditions. In addition, the heat transfer model does not include heat transfer methods for $\mathrm{CO}_{2}$ in mist flow and bubbly flow regimes due to the lack of the experimental data in these regimes, which were not available at that time. Therefore, it is necessary to update the heat transfer model for $\mathrm{CO}_{2}$ to cover a wider range of conditions and these flow regimes and an updated version of the Cheng et al. evaporation model was developed [18]. A flow pattern based two-phase pressure drop model was also needed for $\mathrm{CO}_{2}$ was developed by Cheng et al. [19] as well. 


\section{A General Gas-Liquid Two Phase Flow Pattern Map for $\mathrm{CO}_{2}$ Evaporating inside Tubes}

Flow patterns are very important in understanding the very complex two-phase flow phenomena and heat transfer trends in evaporation heat transfer [7, 8, 11-19]. To predict the local flow patterns in a channel, a flow pattern map is used. In fact, successful flow pattern based evaporation heat transfer and two-phase frictional pressure drop models [38-39, 41-46, 50, 51] have been proposed in recent years. Over the past decades, many flow pattern maps have been developed to predict twophase flow patterns in horizontal tubes $[13,15]$. Most were developed for adiabatic conditions and then extrapolated by users to diabatic conditions, thereby creating big discrepancies [41-43]. For this reason, a number of diabatic flow pattern maps related to the corresponding heat transfer mechanisms have been developed [38-39]. However, none of these is applicable to $\mathrm{CO}_{2}$ evaporation in horizontal tubes because the two-phase flow characteristics of $\mathrm{CO}_{2}$ evaporation are greatly affected by the very high reduced pressures and low surface tensions of $\mathrm{CO}_{2}$. In addition, the very low viscosities of $\mathrm{CO}_{2}$ at high reduced pressures may affect the two-phase pressure drop greatly.

Cheng et al. $[18,19]$ proposed a new flow pattern map and a new general evaporation heat transfer model, flow pattern map and two-phase frictional pressure drop model for $\mathrm{CO}_{2}$ in macro- and micro-scale channels to meet the wide range of parameters used in practical applications. The details of the flow pattern map are presented in this section and the evaporation and two phase pressure drop models are respectively presented in the following sessions. The physical properties of $\mathrm{CO}_{2}$ have been obtained from REFPROP version 6.01 of NIST [39]. The flow pattern map is intrinsically related to the evaporation heat transfer model and the two phase frictional pressure drop model.

For non-circular channels, equivalent diameters rather than hydraulic diameters were used in the flow pattern map $[16-19,44,45]$ as

$$
D_{e q}=\sqrt{\frac{4 A}{\pi}}
$$

Using the equivalent diameter gives the same mass velocity as in the non-circular channel and thus correctly reflects the mean liquid and vapor velocities, something using hydraulic diameter in a two-phase flow does not. In the updated $\mathrm{CO}_{2}$ flow pattern map, several new features were developed as compared to the Cheng et al. flow pattern map [16, 18]:

(1) Combining with the updated flow boiling heat transfer model for $\mathrm{CO}_{2}$, the annular flow to dryout region (A-D) transition boundary was further modified so as to better fit the sharp changes in flow boiling heat transfer characteristics for higher mass velocities;

(2) Based on experimental heat transfer data, a new criterion for the dryout region to mist flow (D-M) transition was proposed;

(3) Bubbly flow occurs at very high mass velocities and very low vapor qualities and a bubbly flow pattern boundary was integrated into the map to make it more complete.

The intermittent to annular flow (I-A) transition boundary is calculated with the Cheng et al. criterion [26, 27]:

$$
x_{I A}=\left[1.8^{1 / 0.875}\left(\frac{\rho_{V}}{\rho_{L}}\right)^{-1 / 1.75}\left(\frac{\mu_{L}}{\mu_{V}}\right)^{-1 / 7}+1\right]^{-1}
$$

Then, the transition boundary is extended down to its intersection with $G_{\text {strat }}$.

The annular flow to dryout region (A-D) transition boundary is calculated with the new modified criterion of Wojtan et al. [34] based of the dryout data of $\mathrm{CO}_{2}$ :

$$
G_{\text {dryout }}=\left\{\frac{1}{0.236}\left[\ln \left(\frac{0.58}{x}\right)+0.52\right]\left(\frac{D_{e q}}{\rho_{V} \sigma}\right)^{-0.17}\left[\frac{1}{g D_{e q} \rho_{V}\left(\rho_{L}-\rho_{V}\right)}\right]^{-0.17}\left(\frac{\rho_{V}}{\rho_{L}}\right)^{-0.25}\left(\frac{q}{q_{\text {crit }}}\right)^{-0.27}\right\}^{1.471}
$$

which is extracted from the new dryout inception equation by Cheng et al. [16]: 


$$
x_{d i}=0.58 e^{\left[0.52-0.236 \mathrm{We}_{V}{ }^{0.17} \mathrm{Fr}_{V, \text { Mori }}{ }^{0.17}\left(\rho_{V} / \rho_{L}\right)^{0.25}\left(q / q_{\text {crit }}\right)^{0.27}\right]}
$$

The dryout region to mist flow (D-M) transition boundary is calculated with the new criterion developed in this study based on the dryout completion data for $\mathrm{CO}_{2}$ :

$$
G_{M}=\left\{\frac{1}{0.502}\left[\ln \left(\frac{0.61}{x}\right)+0.57\right]\left(\frac{D_{e q}}{\rho_{V} \sigma}\right)^{-0.16}\left[\frac{1}{g D_{e q} \rho_{V}\left(\rho_{L}-\rho_{V}\right)}\right]^{-0.15}\left(\frac{\rho_{V}}{\rho_{L}}\right)^{0.09}\left(\frac{q}{q_{c r i t}}\right)^{-0.72}\right\}^{1.613}
$$

which is extracted from the dryout completion (which means the wall remains completely dry) equation developed in this study by solving for $G_{M}$ from:

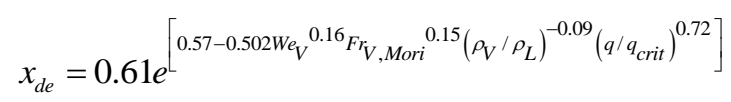

The intermittent to bubbly flow (I-B) transition boundary is calculated with the criterion which arises at very high mass velocities and low qualities [36-38]:

$$
G_{B}=\left\{\frac{256 A_{V D} A_{L D}^{2} D_{e q}^{1.25} \rho_{L}\left(\rho_{L}-\rho_{V}\right) g}{0.3164(1-x)^{1.75} \pi^{2} P_{i D} \mu_{L}^{0.25}}\right\}^{1 / 1.75}
$$

Gashe [47] conducted an experimental study of $\mathrm{CO}_{2}$ evaporation inside a $0.8 \mathrm{~mm}$ diameter rectangular channel for various mass velocities and observed flow patterns by flow visualization as well. The updated $\mathrm{CO}_{2}$ flow pattern map was compared to his observations. It should be mentioned here that different names for the same flow patterns are used by different authors. Gasche in particular used the definition of plug flow, which is an intermittent flow in our flow pattern map. Just to show one example, Figure 20 shows the observed flow patterns of $\mathrm{CO}_{2}$ by Gashe for $D_{e q}=0.833 \mathrm{~mm}$ (equivalent diameter is used here for the rectangular channel). It should be mentioned that the observed slug/annular flow of Gashe is counted as an annular flow in the updated flow pattern map. From the photographs in Fig. 4, it seems that the annular flow is the predominant flow in the slug/annular flow defined by Gashe. The observations (3) and (4) are near their correct regimes, especially by the typical flow pattern map standards. Statistically, $82 \%$ of the total 28 flow pattern data of Gashe [47] are identified correctly by the updated flow map, or more specifically, $75 \%$ of the intermittent flows and $88 \%$ of the annular (slug/annular flow) flows [47]. The updated $\mathrm{CO}_{2}$ flow pattern map thus predicts the flow patterns observed by Gasche rather well. The lack of other new data in the literature should justify future experimental studies to obtain more. Furthermore, it is commonly understood that flow pattern transitions do not occur abruptly but over a range of conditions to complete the transition from one stable regime to the other, whereas transition lines on a map only represent the probable "centerline" of this transition range. With the limited data available for $\mathrm{CO}_{2}$ at this point, predicting the "width" of a transition zone around the transition line is not yet feasible, but it should be a good topic for future research. 


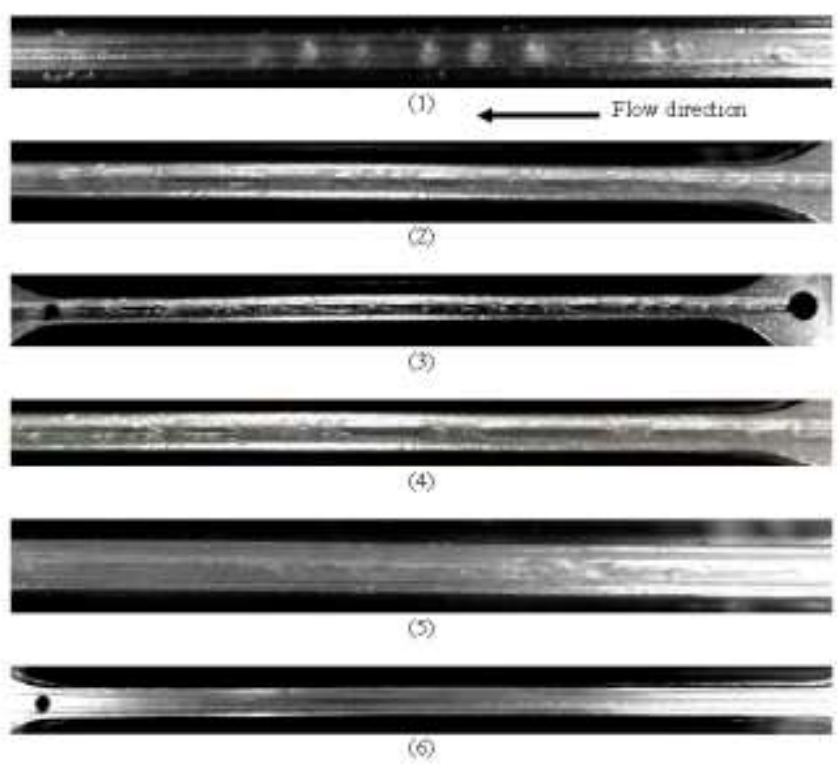

Fig. 4: Flow patterns observed by Gasche [47] at the experimental conditions: $G=149 \mathrm{~kg} / \mathrm{m}^{2} \mathrm{~s}, T_{\text {sat }}=23.3{ }^{\circ} \mathrm{C}, D_{e q}=0.833 \mathrm{~mm}, q=1.86$ $\mathrm{kW} / \mathrm{m}^{2}$ where (1), (2), (3) and (4) — plug flow; (5) — slug/annular flow; (6) — annular flow.

\section{A General Flow Pattern Based Evaporation Heat Transfer Model for $\mathrm{CO}_{2}$}

A general updated general evaporation heat transfer model was developed by modifying the Cheng et a. [16, 17] flow boiling heat transfer model $[18,19]$. By incorporating the updated new flow pattern map in the above section, the new heat transfer model is physically related to the flow regimes of $\mathrm{CO}_{2}$ evaporation, and thus correspondingly the new model has been extended to a wider range of conditions and to include new heat transfer methods in mist flow and bubbly flow regimes. The proposed new general flow boiling heat transfer model predicted reasonably well an extensive experimental database derived from the literature.

To develop a general evaporation heat transfer prediction method, it is important that the method is not only numerically accurate but that it also correctly captures the trends in the data to be useful for heat exchanger optimization. Most importantly, the evaporation heat transfer mechanisms should be related to the corresponding flow patterns and be physically explained according to flow pattern transitions. Besides significantly extending the range of the heat transfer database here, several new modifications were implemented in the updated general evaporation heat transfer model and will be presented below. Changes to the flow pattern map also have an effect on the heat transfer model: the new dryout inception vapor quality correlation (Eq. (5)) and a new dryout completion vapor quality correlation (Eq. (5)) are used to better segregate the data into these regimes, which have sharply different heat transfer performances. Accordingly, the evaporation heat transfer correlation in the dryout region was updated. In addition, a new mist flow heat transfer correlation for $\mathrm{CO}_{2}$ was developed based on the $\mathrm{CO}_{2}$ data and a heat transfer method for bubbly flow was adopted for completeness sake. With these modifications, a new general evaporation heat transfer model for $\mathrm{CO}_{2}$ was developed to meet a wider range of conditions and to cover all flow regimes $[18,19]$.

The general equation for the local flow boiling heat transfer coefficients $h_{t p}$ in a horizontal tube is expressed as [36-38]:

$$
h_{t p}=\frac{\theta_{d r y} h_{V}+\left(2 \pi-\theta_{d r y}\right) h_{w e t}}{2 \pi}
$$

where $\theta_{d r y}$ is the dry angle defined in Fig. 5. The dry angle $\theta_{d r y}$ defines the flow structures and the ratio of the tube perimeter in contact with liquid and vapor. In stratified flow, $\theta_{d r y}$ equals the stratified angle $\theta_{\text {strat }}[16]$. In annular $(A)$, intermittent $(I)$ 
and bubbly $(B)$ flows, $\theta_{d r y}=0$. For stratified-wavy flow, $\theta_{d r y}$ varies from zero up to its maximum value $\theta_{\text {strat }}$. Stratified-wavy flow has been subdivided into three subzones (slug, slug/stratified-wavy and stratified-wavy) to determine $\theta_{d r y}$.

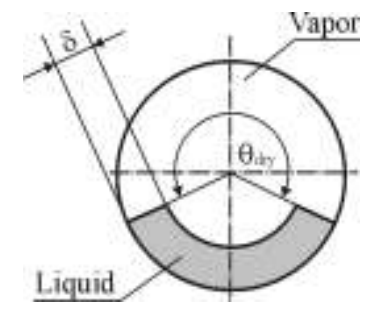

Fig. 5: Schematic diagram of film thickness.

The vapor phase heat transfer coefficient on the dry perimeter $h_{V}$ is calculated with the Dittus-Boelter [48] correlation assuming tubular flow in the tube. The heat transfer coefficient on the wet perimeter $h_{\text {wet }}$ is calculated with an asymptotic model that combines the nucleate boiling and convective boiling heat transfer contributions to flow boiling heat transfer by the third power:

$$
h_{w e t}=\left[\left(S h_{n b}\right)^{3}+h_{c b}{ }^{3}\right]^{1 / 3}
$$

where $h_{n b}, S$ and $h_{c \mathrm{~b}}$ are respectively nucleate boiling heat transfer coefficient, nucleate boiling heat transfer suppression factor and convective boiling heat transfer coefficient and are determined in the following equations

The nucleate boiling heat transfer coefficient $h_{n b}$ is calculated with the Cheng et al. [16] nucleate boiling correlation for $\mathrm{CO}_{2}$ which is a modification of the Cooper [49] correlation:

$$
h_{n b}=131 p_{r}^{-0.0063}\left(-\log _{10} p_{r}\right)^{-0.55} M^{-0.5} q^{0.58}
$$

The Cheng et al. [16] nucleate boiling heat transfer suppression factor $S$ for $\mathrm{CO}_{2}$ is applied to reduce the nucleate boiling heat transfer contribution due to the thinning of the annular liquid film:

$$
\begin{gathered}
\text { If } x<x_{I A}, S=1 \\
\text { If } x \geq x_{I A}, S=1-1.14\left(\frac{D_{e q}}{0.00753}\right)^{2}\left(1-\frac{\delta}{\delta_{I A}}\right)^{2.2}
\end{gathered}
$$

Furthermore, if $D_{e q}>7.53 \mathrm{~mm}$, then set $D_{e q}=7.53 \mathrm{~mm}$. The liquid film thickness $\delta$ shown in Fig. 5 is calculated with the expression proposed by El Hajal et al. [50]:

The convective boiling heat transfer coefficient $h_{c b}$ is calculated with the following correlation assuming an annular liquid film flow from the original model [16, 38]:

$$
h_{c b}=0.0133 \operatorname{Re}_{\delta}^{0.69} \operatorname{Pr}_{L}^{0.4} \frac{k_{L}}{\delta}
$$

The heat transfer coefficient in the dryout region is calculated by a linear interpolation proposed by Wojtan et al. [35]. A heat transfer model for bubbly flow was added to the model for completeness sake. In the absence of any data, the heat transfer coefficients in bubbly flow regime are calculated by the same method as that in the intermittent flow. Eq. (9) is used to calculate the local flow boiling heat transfer coefficients. In bubbly $(B)$ flow, the dryout angle $\theta_{d r y}=0$.

The updated general flow boiling heat transfer model was compared to an extensive database [19]. Just to show one example here, Figure 6(a) shows the comparison of the predicted flow boiling heat transfer coefficients to the experimental 
data of Yun et al. [25] and Figure 6(b) shows the corresponding flow map. The updated general flow boiling heat transfer model not only captures the heat transfer trends well but also predicts the experimental heat transfer data well. As it is harder to predict (and harder to accurately measure) heat transfer data in the dryout and mist flow regimes, the updated general heat transfer model does not always predict the experimental data in these two flow regimes satisfactorily. Some examples of such comparisons can be found in [19].

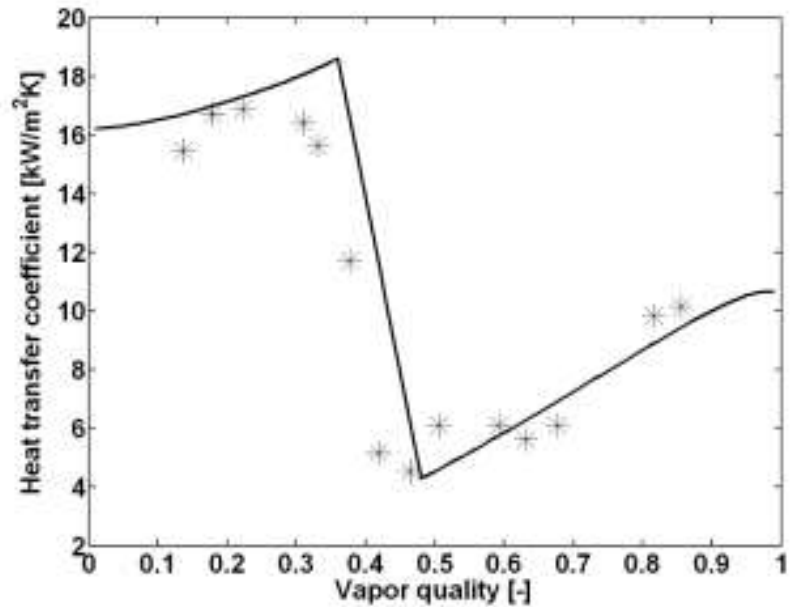

(a)

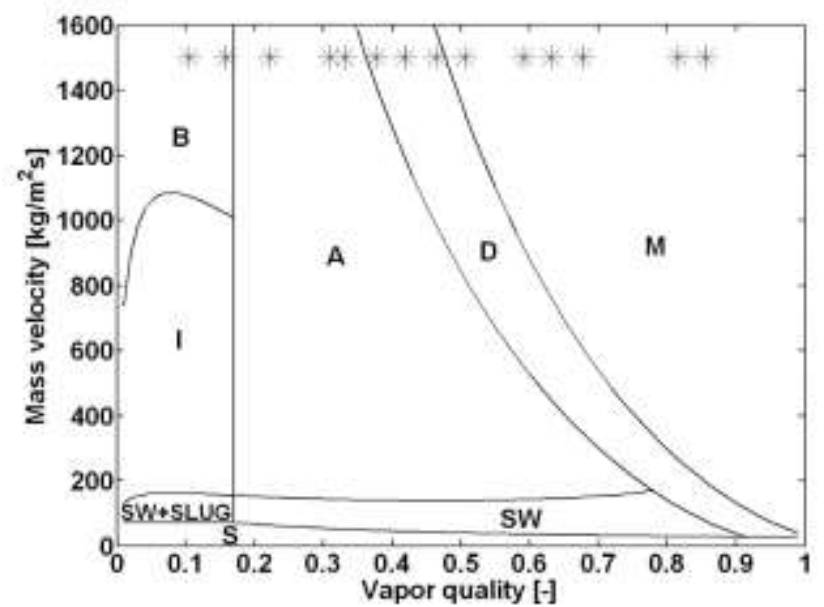

(b)

Fig. 6: (a) Comparison of the predicted flow boiling heat transfer coefficients to the experimental data of Yun et al. [25]; (b) the corresponding flow pattern map (at the test conditions: $D_{e q}=2 \mathrm{~mm}, q=30 \mathrm{~kW} / \mathrm{m}^{2}, T_{\text {sat }}=5^{\circ} \mathrm{C}$ and $G=1500 \mathrm{~kg} / \mathrm{m}^{2} \mathrm{~s}$.

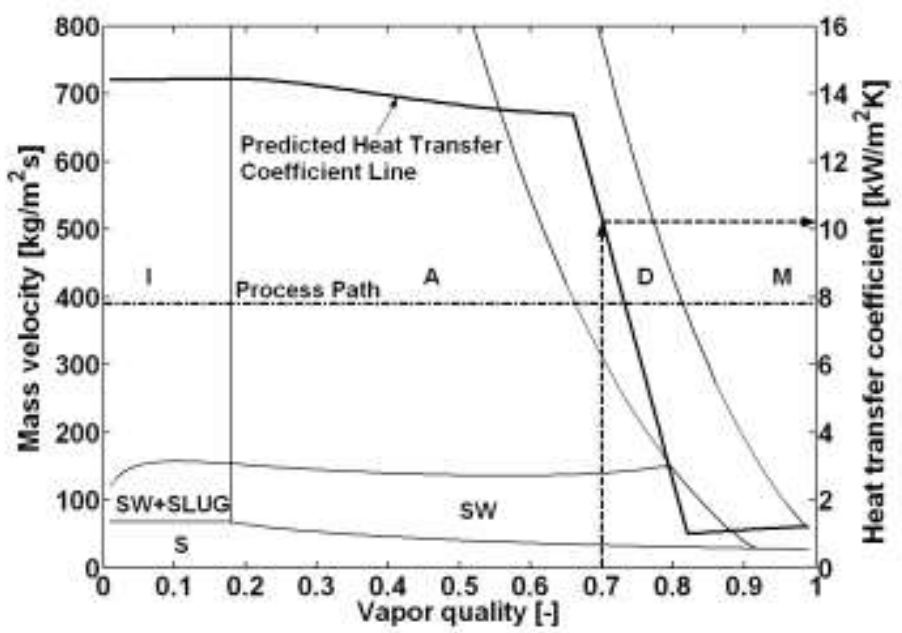

Fig. 7: Simulation of flow boiling heat transfer model and flow pattern map for $3 \mathrm{~mm}$ channel at the conditions: $q=20 \mathrm{~kW} / \mathrm{m}^{2}, T_{\text {sat }}=$ $10^{\circ} \mathrm{C}$ and $G=390 \mathrm{~kg} / \mathrm{m}^{2} \mathrm{~s}$ with indicated value at $x=0.70[51]$.

In further analysis, comparisons have also been made by classes of flows, i.e. the predictions versus all the heat transfer data excluding dryout and mist flow data (essentially the all wet perimeter data), versus all dryout heat transfer data (the partially wet perimeter data) and versus the mist flow data (all dry perimeter data) [19]. The statistical analysis has shown the following fraction of the database are predicted within $\pm 30 \%: 71.4 \%$ of the entire database (1124 points), $83.2 \%$ of the all wet wall data points ( 773 points), $47.6 \%$ of the partially wet wall data points (191 points) and $48.2 \%$ of the all dry wall data points (160 points) [19]. Overall, the updated general flow boiling heat transfer model predicts the overall database quite well. However, for the dryout and mist flow regimes with partially or all dry perimeters, the heat transfer model is only 
partially satisfactory. For these last two regimes, many of the experimental data sets have a level of scatter ranging up $40 \%$ themselves. In part, the larger errors are due to the very sharp change in trend in these data with vapor quality, where an error of a 2-3\% in vapor quality in the energy balance of the experiments or in the prediction of $x_{d i}$ and/or $x_{d e}$ immediately results in a heat transfer prediction error of 50\%. Therefore, more careful experiments are needed in these two regimes to provide more accurate heat transfer data, with attention to also determine the transitions $x_{d i}$ and $x_{d e}$, because they are typical working conditions in the micro-scale channels of extruded multi-port aluminum tubes used for automobile air-conditioners that operate over a wide range of mass velocities up to as high as $1500 \mathrm{~kg} / \mathrm{m}^{2} \mathrm{~s}$.

Figure 7 shows simulation of the updated flow pattern map and flow boiling model for $\mathrm{CO}_{2}$ at the indicated conditions, superimposed on the same graphs by Cheng et al. [51]. The process path for the vapor quality variation from $\mathrm{x}=0.01$ to $\mathrm{x}=$ 0.99 is shown as the horizontal broken line (dash-dot line) while the variation in the heat transfer coefficient as it changes vapor quality and flow pattern is depicted by the dashed line. The flow pattern boundaries are in solid lines. The line (dash line with arrows) indicates the calculated heat transfer coefficient at the indicated mass velocity and vapor quality. Notice the various changes in trends in the heat transfer coefficient as this occurs. For example, when the flow regime passes from annular flow into the dryout regime, there is a sharp inflection in the heat transfer coefficient as the top perimeter of the tube becomes dry. A number of existing studies have confirmed that the Cheng et al. [16-19] $\mathrm{CO}_{2}$ flow boiling heat transfer model has favorably predicted their experimental data [54-56]. Th prediction of flow boiling heat transfer is a big challenge depending of the various fluids and conditions [52]. In particular, the microchannel effects become significant and need to be well understood [53].

\section{Simulations of $\mathrm{CO}_{2}$ Thermal Systems Using the Cheng et al. Models}

The Cheng et al. flow pattern based evaporation heat transfer and two phase frictional pressure drop models for have been widely used for simulations of $\mathrm{CO}_{2}$ refrigeration, air-conditioning and heat pump systems by a number of researchers [61-65]. For example, in order to improve the system performance of the $\mathrm{CO}_{2}$ heat pump, it is necessary to develop an optimum design and a control method for the $\mathrm{CO}_{2}$ heat pump water heater. Yamaguchi et al. [62] have developed a highprecision and general-purpose system simulation model for the $\mathrm{CO}_{2}$ heat pump water heater and investigated the validity of the model with detailed experiments. Figure 8 shows the system flow diagram of the $\mathrm{CO}_{2}$ heat pump water heater in their study This system consists of a gas cooler, an evaporator, an internal heat exchanger, a compressor, and an expansion valve. In the internal heat exchanger, the refrigerant from the evaporator cools the refrigerant that flows in from the gas cooler, and then flows into the compressor, where its pressure and temperature are increased. The heated refrigerant then flows into the gas cooler, where it heats up the supplied water. Subsequently, it flows into the internal heat exchanger and is expanded by the expansion valve. Finally, the refrigerant flows into the evaporator. In the evaporator, the refrigerant absorbs heat from the ambient air, after which it flows back to the internal heat exchanger. In this system, a cross-finned tube heat exchanger with smooth plate fins is adapted for use in the evaporator as shown in Fig. 8.
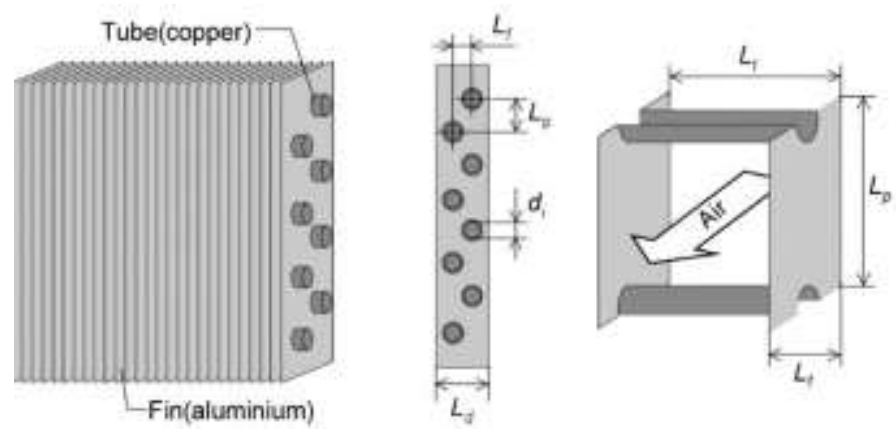

Fig. 8: System flow diagram of $\mathrm{CO}_{2}$ heat pump and measuring points in the study of Yamaguchi et al. [62]. 


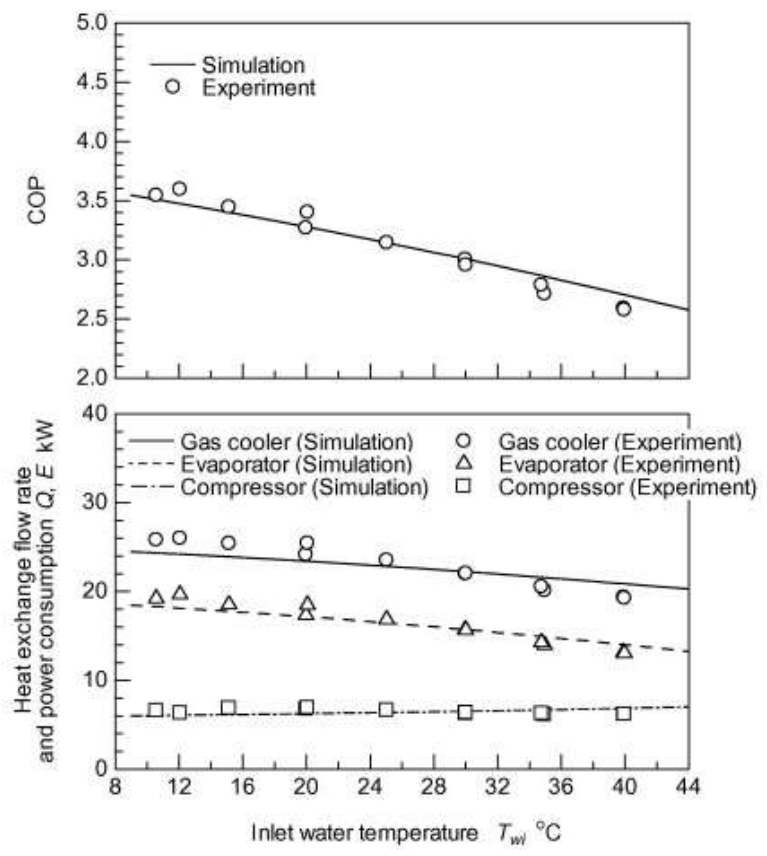

Fig. 9: The effect of the water inlet temperature the COP and heat flow rate [62].

A cross-finned tube heat exchanger with smooth plate fins is adapted for use in the evaporator in the heat pump system as shown in Fig. 9. In the development of their model, the local heat transfer coefficient and two phase frictional pressure drop inside the tubes are calculated using the Cheng et al. flow pattern based evaporation heat transfer model [18, 19]. This models were developed specifically for $\mathrm{CO}_{2}$ to predict the evaporation heat transfer coefficient and the two phase frictional pressure drop on the basis of the flow pattern map for $\mathrm{CO}_{2}$. They also considered the oil effect on the performance. In comparison of predicted and measured values, it is confirmed that the predicted values are in good agreement with the measured values totally. For evaporator, the results show good agreement between the measured and predicted heat transfer rate. This means that the Cheng et al. models work well in this study. The maximum difference between the predicted and measured COP is $5.4 \%$, and the average difference is $0.9 \%$.

Considering the actual heat transfer processes of heat exchangers and characteristics of components adopted in the cycle of air-source trans-critical $\mathrm{CO}_{2}$ heat pump water heater system, Wang et al. [63] conducted simulation for the heat pump cycle. In their simulation model, the Cheng et al. flow pattern based evaporation model was adopted in the evaporator model in their simulation. It shows good agreement with the experimental results. Faria et al. [64] investigated of the behaviour of the solar evaporator and expansion valve assembly of a transcritical $\mathrm{CO}_{2}$ heat pump in transient and steady conditions. The dynamic behaviour of systems using $\mathrm{CO}_{2}$ as a refrigerant is significantly influenced by the dynamics of the heat transfer mechanisms. The solar evaporator model is based on the equations of conservation of mass, momentum, and energy. The model validation is realized by comparing simulation results with the Cheng et al. models and the experimental data. The model is a useful tool for analysing the behaviour in transient and steady conditions simulating various operating conditions of the heat pump including solar radiation, ambient temperature, wind speed and atmospheric conditions. Yang et al. [65] investigated experimentally a prototype of combined $\mathrm{R} 134 \mathrm{a}$ and transcritical $\mathrm{CO}_{2}$ heat pump. The experimental results demonstrated that the combined system could operate reliably and supply stable temperature hot water over a wide range of ambient temperatures and feed water temperatures. The experimental results also showed that ambient temperature had a large effect on the system performance. Furthermore, they investigated the improvement of the combined system in comparison to the standard transcritical $\mathrm{CO}_{2}$ heat pump, a simple mathematical model was developed and validated by the experimental data. The comparison results showed that the combined system could offer higher system COP at experimental ambient and feed water temperatures. In their evaporator model, the Cheng et al. models were used in the simulations. In general, the Cheng et al. flow pattern-based evaporation heat transfer and two-phase pressure drop models [16-19] show good agreement with the experimental data in the existing studies when used in modeling the evaporators in these systems. 
As an excellent coolant, $\mathrm{CO}_{2}$ may be used in electronic cooling [5], two-phase thermosyphon loop [66, 68] and evaporative $\mathrm{CO}_{2}$ cooling system for the upgrade of the CMS pixel detector [69] etc. Furthermore, new applications with $\mathrm{CO}_{2}$ in various thermal systems with microscale channel evaporators should be further explored to improve the energy efficiency and environmental safe. According to the existing studies, it has confirmed that the Cheng et al. models favourably predict the evaporation heat transfer, two phase pressure drop and flow patterns in heat exchanger tubes. This also means that the mechanistic models relating the flow patterns to the corresponding heat transfer coefficients and two phase pressure drops are promising methods. Therefore, more accurate flow pattern observations and heat transfer and pressure drop experimental data under a wide range test conditions are still needed. Furthermore, understanding the oil effects on the two phase flow and heat transfer of $\mathrm{CO}_{2}$ and relevant practical models are also needed [61, 67]. New thermal and energy systems should also be targeted to extend the applications of $\mathrm{CO}_{2}$ in industry.

\section{Concluding Remarks}

A general $\mathrm{CO}_{2}$ two-phase flow patterns and models of $\mathrm{CO}_{2}$ evaporation heat transfer and two phase frictional pressure drops in macroscale- and microscale-channels and their applications in modeling and designing $\mathrm{CO}_{2}$ evaporators in refrigeration, air-conditioning and heat pump systems are presented. The available experimental studies are analysed at first. Then, the Cheng et al. models of two-phase flow pattern map for $\mathrm{CO}_{2}$ evaporation, flow pattern-based flow boiling heat transfer are presented. Furthermore, modeling of $\mathrm{CO}_{2}$ evaporation and simulation/design of $\mathrm{CO}_{2}$ evaporators are reviewed and analysed. The research needs in the future are identified. Finally, $\mathrm{CO}_{2}$ evaporator design and selection are presented for the practical application. The main conclusions are summarized as follows:

(1) According to comprehensive literature review, the available experimental results have shown different evaporation heat transfer and two-phase flow characteristics of $\mathrm{CO}_{2}$ at high and low reduced pressures. The evaporation heat transfer and two-phase flow of $\mathrm{CO}_{2}$ at saturation temperatures ranging from 0 to $25^{\circ} \mathrm{C}$ show different characteristics from those of conventional refrigerants due to the significant differences in thermal physical and transport properties. $\mathrm{CO}_{2}$ has much higher evaporation heat transfer and much lower two phase frictional pressure drops than other low-pressure refrigerants such as R134a and ammonia etc. The evaporation heat transfer mechanisms are the dominance of the nucleate boiling at low/moderate vapor qualities prior to dryout and the occurrence of dryout in $\mathrm{CO}_{2}$ at relatively lower vapor qualities than conventional refrigerants. Furthermore, the effect of the saturation temperature on the evaporation heat transfer coefficient is more noticeable. At high saturation temperatures, the nucleate boiling mechanism is more pronounced at low vapor qualities.

(2) The experimental data from the different independent studies show somewhat different evaporation heat transfer trends at similar test conditions. It is difficult to explain the differences at similar conditions or the parameter effects on the evaporation heat transfer behaviors according to the physical mechanisms. This might be caused by large measurement uncertainties. Therefore, more accurate experimental data are needed for $\mathrm{CO}_{2}$ evaporation in both macro- and micro-channels through well designed test facilities and careful experiments. In particular, a wide range of test conditions should be designed to meet the practical needs in industry.

(3) Overall, the Cheng et al. general flow pattern map and flow pattern based evaporation heat transfer model for $\mathrm{CO}_{2}$ reasonably predicts the observed flow patterns and experimental heat transfer coefficients in the literature and also capture properly the parametric trends. However, for the dryout and mist flow regimes with partially or all dry perimeters, the heat transfer model is only partially satisfactory. Therefore, more careful experiments are needed in these two regimes to provide more accurate heat transfer data, with attention to also determine the transitions $x_{d i}$ and $x_{d e}$, because they are typical working conditions in the micro-scale channels of extruded multi-port tubes used for refrigerant, automobile air-conditioning and refrigeration systems that operate over a wide range of mass velocities up to as high as $1500 \mathrm{~kg} / \mathrm{m}^{2} \mathrm{~s}$.

(4) The Cheng et al. flow pattern based $\mathrm{CO}_{2}$ two-phase flow pressure drop model predicts the $\mathrm{CO}_{2}$ pressure drop database better than the existing methods. Due to the very few and less accurate experimental data in micro-scale channels currently available, it is suggested that additional, more accurate experimental $\mathrm{CO}_{2}$ pressure drop data be obtained to further test or improve the model in the future.

(5) The Cheng et al. flow pattern based $\mathrm{CO}_{2}$ evaporation heat transfer and two-phase flow pressure drop models have been adopted in the simulations of evaporators in various thermal systems by a number of researchers. It shows that the experimental results favourably agree with the simulations results. Therefore, it is recommended that Cheng et al. methods be used in the design and simulation of $\mathrm{CO}_{2}$ evaporators. 
(6) As an excellent working fluid, $\mathrm{CO}_{2}$ has also been investigated in other practical applications such as electronic chips cooling, evaporative $\mathrm{CO}_{2}$ cooling system for the upgrade of the CMS pixel detector and potential for renewable energy and power generation. Therefore, effort should be made to explore new applications of $\mathrm{CO}_{2}$ evaporation in the relevant fields.

\section{References}

[1] J. R. Thome, G. Ribatski, "State-of-the-art of two-phase flow and flow boiling heat transfer and pressure drop of $\mathrm{CO}_{2}$ in macro- and micro-channels," Int. J. Refrigeration, vol. 28, pp. 1149-1168, 2005.

[2] J. R. Thome, L. Cheng, G. Ribatski, L. F. Vales, "Flow boiling of ammonia and hydrocarbons: A state-of-the-art review," Int. J. Refrigeration, vol. 31, pp. 603-620, 2008.

[3] M. H. Kim, J. Pettersen, C. W. Bullard, "Fundamental process and system design issues in CO2 vapor compression systems," Progr. Energy Comb. Sci., vol. 30, pp. 119-174, 2000.

[4] L. Cheng, G. Ribatski, J. R. Thome, "Analysis of supercritical $\mathrm{CO}_{2}$ cooling in macro- and micro Channels," In. J. Refrigeration, vol. 31, pp. 1301-1316, 2008.

[5] L. Cheng, J. R. Thome, "Cooling of microprocessors using flow boiling of $\mathrm{CO}_{2}$ in micro-evaporators: Preliminary analysis and performance comparison," Appl. Therm. Eng., vol. 29, pp. 2426-2432, 2009.

[6] L. Cheng, "Evaluation of correlations for supercritical $\mathrm{CO}_{2}$ cooling convective heat transfer and pressure drop in macro- and micro-scale tubes," Int. J. Microscale Nanoscale Thermal Fluid Transport Phenomena, vol. 5, no. 2, 113 126. 2014

[7] L. Cheng, G. Xia, "Fundamental issues, mechanisms and models of flow boiling heat transfer in microscale channels," Int. J. Heat Mass Transfer, vol. 108 Part A, pp. 97-127, 2017.

[8] L. Cheng, "Fundamental issues of critical heat flux phenomena during flow boiling in microscale-channels and nucleate pool boiling in confined spaces," Heat Transfer Eng., vol. 34, no. 13, pp. 1011-1043, 2013.

[9] S. G. Kandlikar, "Fundamental issues related to flow boiling in minichannels and microchannels," Exp. Therm. Fluid Sci., vol. 26, pp. 389-407, 2002.

[10] P. A. Kew, K. Cornwell, "Correlation for the prediction of boiling in small-diameter channels," Appl. Therm. Eng., vol. 17, pp. 705-715, 1997.

[11] L. Cheng, D. Mewes, A. Luke, "Boiling phenomena with surfactants and polymeric additives: A state-of-the-art review," Int. J. Heat Mass Transfer, vol. 50, pp. 2744-2771, 2007.

[12] L. Cheng, D. Mewes, "Review of two-phase flow and flow boiling of mixtures in small and mini channels," Int. J. Multiphase Flow, vol. 32, pp. 183-207, 2006.

[13] L. Cheng, "Microscale Flow Patterns and Bubble Growth in Microchannels," in Microchannel Phase Change Heat Transfer, Sujoy Kumar Saha, Ed. Elsevier Publisher, 2016, pp. 91-140.

[14] L. Cheng, "Flow Boiling Heat Transfer with Models in Microchannels," in Microchannel Phase Change Heat Transfer, Sujoy Kumar Saha, Ed. Elsevier Publisher, 2016, pp. 141-191.

[15] L. Cheng, G. Ribatski, J. R. Thome, "Gas-liquid two-phase flow patterns and flow pattern maps: fundamentals and applications," ASME Appl. Mech. Rev., vol. 61, 2008.

[16] L. Cheng, G. Ribatski, L. Wojtan, J. R. Thome, "New flow boiling heat transfer model and flow pattern map for carbon dioxide evaporating inside horizontal tubes," Int. J. Heat Mass Transfer, vol. 49, pp. 4082-4094, 2006.

[17] L. Cheng, G. Ribatski, L. Wojtan, J. R. Thome, "Erratum to: New flow boiling heat transfer model and flow pattern map for carbon dioxide evaporating inside tubes," [Heat Mass Transfer 49 (21-22) (2006) 4082-4094]. Int. J. Heat Mass Transfer, vol. 50, pp. 391, 2007.

[18] L. Cheng, G. Ribatski, J. Moreno Quibén, J. R. Thome, "New prediction methods for $\mathrm{CO}_{2}$ evaporation inside tubes: Part I - A general two-phase flow pattern map and development of a phenomenological model of two-phase flow frictional pressure drop," Int. J. Heat Mass Transfer, vol. 51, pp. 111-124, 2008.

[19] L. Cheng, G. Ribatski, J. R. Thome, "New prediction methods for $\mathrm{CO}_{2}$ evaporation inside tubes: Part II - A general flow boiling heat transfer model based on flow patterns," Int. J. Heat Mass Transfer, vol. 51, pp. 125-135, 2008.

[20] J. Pettersen, "Flow vaporization of $\mathrm{CO}_{2}$ in microchannel tubes," Exp. Therm. Fluid Sci., vol. 28, pp. 111-121, 2004.

[21] R. Yun, Y. Kim, M. S. Kim, Y. Choi, "Boiling heat transfer and dryout phenomenon of $\mathrm{CO}_{2}$ in a horizontal smooth tube," Int. J. Heat Mass Transfer, vol. 46, pp. 2353-2361, 2003. 
[22] R. Yun, Y. Kim, M. S. Kim, "Flow boiling heat transfer of carbon dioxide in horizontal mini tubes," Int. J. Heat Fluid Flow, vol. 26, pp. 801-809, 2005.

[23] E. Hihara, S. Tanaka, "Boiling heat transfer of carbon dioxide in horizontal tubes," in Preliminary Proceedings of IIR Gustav Lorentzen Conference on Natural Working Fluids, Purdue, 2000, pp. 279-284.

[24] S. H. Yoon, E. S. Cho, Y. W. Hwang, M. S. Kim, K. Min, Y. Kim, "Characteristics of evaporative heat transfer and pressure drop of carbon dioxide and correlation development," Int. J. Refrigeration, vol. 27, pp. 111-119, 2004.

[25] R. Yun, Y. Kim, M. S. Kim, "Convective boiling heat transfer characteristics of $\mathrm{CO}_{2}$ in microchannels," Int. J. Heat Mass Transfer, vol. 48, pp. 235-242, 2005.

[26] S. Koyama, K. Kuwahara, E. Shinmura, S. Ikeda, "Experimental study on flow boiling of carbon dioxide in a horizontal small diameter tube," in IIR Commission B1 Meeting, Paderborn, Germany, 2001, pp. 526-533.

[27] E. Hihara, "Fundamental technology for carbon dioxide operated heat pumps," in JSAE Automotive Air-Conditioning Symposium, 2006, pp. 243-262.

[28] A. Bredesen, A. Hafner, J. Pettersen, P. Neksa, K. Aflekt, "Heat transfer and pressure drop for in-tube evaporation of $\mathrm{CO}_{2}$," in Proceedings of the International Conference on Heat Transfer Issues in Natural Refrigerants, University of Maryland, USA, 1997, pp. 1-15.

[29] H. J. Knudsen, R. H. Jensen, "Heat transfer coefficient for boiling carbon dioxide," in Workshop Proceedings - CO Technologies in Refrigeration, Heat Pumps and Air Conditioning Systems, Trondheim, Norway, 1997, pp. 319-328.

[30] X. Zhao, P. K. Bansal, "Flow boiling heat transfer characteristics of $\mathrm{CO}_{2}$ at low temperatures," Int. J. Refrigeration, vol. 30, pp. 937-945, 2007.

[31] C. Y. Park, P. S. Hrnjak, "Flow boiling heat transfer of $\mathrm{CO}_{2}$ at low temperatures in a horizontal smooth tube," J. Heat Transfer, vol. 127, pp. 1305-1312, 2005.

[32] S. Koyama, S. Lee, D. Ito, K. Kuwahara, H. Ogawa, "Experimental study on flow boiling of pure $\mathrm{CO}_{2}$ and $\mathrm{CO}_{2}$-oil mixtures inside horizontal smooth and micro-fin copper tubes," in Proceedings of $6^{\text {th }}$ IIT-Gustav Lorentzen Conference, Glasgow, UK, 2004.

[33] J. M. Cho, M. S. Kim, "Experimental studies on the evaporative heat transfer and pressure drop of $\mathrm{CO}_{2}$ in smooth and micro-fin tubes of the diameters of 5 and 9.52 mm," Int. J. Refrigeration. vol. 30, pp. 986-994, 2007.

[34] L. Wojtan, T. Ursenbacher, J. R. Thome, "Investigation of flow boiling in horizontal tubes: Part I - A new diabatic two-phase flow pattern map," Int. J. Heat Mass Transfer, vol. 48, pp. 2955-2969, 2005.

[35] L. Wojtan, T. Ursenbacher, J. R. Thome, "Investigation of flow boiling in horizontal tubes: Part II - Development of a new heat transfer model for stratified-wawy, dryout and mist flow regimes," Int. J. Heat Mass Transfer, vol. 48, pp. 2970-2985, 2005.

[36] N. Kattan, J. R. Thome, D. Favrat, "Flow boiling in horizontal tubes. Part 1: Development of a diabatic two-phase flow pattern map," J. Heat Transfer, vol. 120, pp. 140-147, 1998.

[37] N. Kattan, J. R. Thome, D. Favrat, "Flow boiling in horizontal tubes: Part 2-New heat transfer data for five refrigerants," J. Heat Transfer, vol. 120, pp. 148-155, 1998.

[38] N. Kattan, J. R. Thome, D. Favrat, "Flow boiling in horizontal tubes: Part-3: Development of a new heat transfer model based on flow patterns," J. Heat Transfer, vol. 120, pp. 156-165, 1998.

[39] REFPROP. NIST Refrigerant Properties Database 23. Gaithersburg, MD, 1998, Version 6.01.

[40] J. C. Chen, "Correlation for boiling heat transfer to saturated fluids in convective flow," Ind. Chem. Eng. Des. Dev., vol. 5, pp. 322-339, 1966.

[41] Y. Taitel, A. E. Dukler, "A model for predicting flow regime transitions in horizontal and near horizontal gas-liquid flow," AIChE J., vol. 22, pp. 47-55, 1976.

[42] K. Hashitume, "Flow pattern and void fraction of refrigerant two-phase flow in a horizontal pipe," Bulletin of the JSME., vol. 26, pp. 1597-1602, 1983.

[43] D. Steiner, "VDI-Wärmeatlas, Verein Deutscher Ingenieure VDI-Gessellschaft Verfahrenstechnik und Chemieingenieurwessen (GCV), Düsseldorf, Ch. Hbb, 1993.

[44] J. Moreno Quibén, L. Cheng, R. J. da Silva Lima, J. R. Thome, "Flow boiling in horizontal flattened tubes: Part I Two-phase frictional pressure drop results and model," Int. J. Heat Mass Transfer, vol. 52, pp. 3634-3644, 2009.

[45] J. Moreno Quibén, L. Cheng, R. J. da Silva Lima, J. R. Thome, "Flow boiling in horizontal flattened tubes: Part II Flow boiling heat transfer results and model," Int. J. Heat Mass Transfer, vol. 52, pp. 3645-3653, 2009. 
[46] J. R. Thome, J. El Hajal, "Two-phase flow pattern map for evaporation in horizontal tubes: Latest version," in $I^{s t}$ International Conference on Heat Transfer, Fluid Mechanics and Thermodynamics, Kruger Park, South Africa, April 8-10, 2002, pp. 182-188.

[47] J. L. Gasche, "Carbon dioxide evaporation in a single micro-channel," J. Braz. Soc. Mech. Sci. Eng., vol. 28, pp. 6983, 2006.

[48] F. W. Dittus, L. M. K. Boelter, "Heat transfer in automobile radiator of the tubular type," Univ. Calif. Publ. Eng., vol. 2, pp. 443-461, 1930.

[49] M. G. Cooper, "Saturation nucleate pool boiling: a simple correlation," in 1st U.K. National Conference on Heat Transfer, vol. 2, pp. 785-793, 1984.

[50] J. El Hajal, J. R. Thome, A. Cavallini, "Condensation in horizontal tubes, part 2: New heat transfer model based on flow regimes," Int. J. Heat Mass Transfer, vol. 46, pp. 3365-3387, 2003.

[51] L. Cheng, G. Ribatski, J. R. Thome, "On the Prediction of Flow Boiling Heat Transfer of $\mathrm{CO}_{2}$," in $T h e 2^{\text {nd }} I I R$ International Congress of Refrigeration, Beijing, P.R. China, August 21-26, 2007.

[52] L. Cheng, T. Cheng, "Comparison of six typical correlations for upward flow boiling heat transfer with kerosene in a vertical smooth tube," Heat Transfer Eng., vol. 21, no. 5, pp. 27-34, 2000.

[53] L. Cheng, "Microscale and nanoscale thermal and fluid transport phenomena: Rapidly developing research fields," Int. J. Microscale Nanoscale Therm.Trans. Phen, vol. 1, no. 1, pp. 3-6, 2010.

[54] L. Gao, Y. Watanabe T. Honda, " $\mathrm{CO}_{2}$ Flow boiling in small diameter smooth and micro-fin tubes," Journal of JSME., vol. 11, pp. SS66-SS72, 2011.

[55] S. Grauso, R. Mastrullo, A. W. Mauro, G. P. Vanoli, "Flow boiling of R410A and $\mathrm{CO}_{2}$ from low to medium reduced pressures in macro channels: Experiments and assessment of prediction methods," Int. J. Heat Mass Transfer, vol. 56, no. $1-2$, pp. 107-118, 2013.

[56] R. Mastrullo, A. W. Mauro, A. Rosato, G. P. Vanoli, "Carbon dioxide local heat transfer coefficients during flow boiling in a horizontal circular smooth tube," Int. J. Heat Mass Transfer, vol. 52, no. 19-20, pp. 4189-4194, 2009.

[57] R. Mastrullo, A. W. Mauro, A. Rosato, G. P. Vanoli, "Carbon dioxide heat transfer coefficients and pressure drops during flow boiling: Assessment of predictive methods," Int. J. Heat Mass Transfer, vol. 6, pp. 1068-1085, 2010.

[58] J. Wu, T. Koettig, Ch. Franke, D. Helmer, T. Eisel, F. Haug, J. Bremer, "Investigation of heat transfer and pressure drop of $\mathrm{CO}_{2}$ two-phase flow in a horizontal minichannel," Int. J. Heat Mass Transfer, vol. 54, no. 9-10, pp. 154-2162, 2011.

[59] J. Patiño, R. Llopis, D. Sánchez, C. Sanz-Kock, R. Cabello, E. Torrella, “A comparative analysis of a $\mathrm{CO}_{2}$ evaporator model using experimental heat transfer correlations and a flow pattern map," Int. J. Heat Mass Transfer, vol. 71, pp. 361-375, 2014.

[60] M. Wetzel, B. Dietrich, T. Wetzel, "Influence of oil on heat transfer and pressure drop during flow boiling of $\mathrm{CO}_{2}$ at low temperatures," Exp. Therm. Fluid Sci., vol. 59, pp. 202-212, 2014.

[61] J. B. Marcinichen, J. R. Thome, R. H. Pereira, "Working fluid charge reduction, part 1: $\mathrm{CO}_{2}$ fin tube evaporator designed for light commercial appliances utilizing flow pattern based phenomenological prediction models," Int. $J$. Refrig., vol. 65, pp. 258-272, 2016.

[62] S. Yamaguchi, D. Kato, K. Saito, S. Kawai, "Development and validation of static simulation model for $\mathrm{CO}_{2}$ heat pump," Int. J. Heat Mass Transfer, vol. 54, pp. 1986-1906, 2011.

[63] S. Wang, H. Tuo, F. Cao, Z. Xing, "Experimental investigation on air-source transcritical $\mathrm{CO}_{2}$ heat pump water heater system at a fixed water inlet temperature," Int. J. Refrig., vol. 36, pp. 701-716, 2013.

[64] R. N. Faria, R. O. Nunes, R. N. N. Koury, L. Machado, "Dynamic modeling study for a solar evaporator with expansion valve assembly of a transcritical $\mathrm{CO}_{2}$ heat pump," Int. J. Refrig., vol. 64, pp. 203-213, 2016.

[65] D. Yang, Y. Song, F. Cao, L. Jin, X. Wang, "Theoretical and experimental investigation of a combined R134a and transcritical $\mathrm{CO}_{2}$ heat pump for space heating," Int. J. Refrig., vol. 72, pp. 156-170, 2016.

[66] Z. Tong, X. H. Liu, Z. Li, Yi Jiang, "Experimental study on the effect of fill ratio on an R744 two-phase thermosyphon loop," Appl. Therm. Eng., vol. 99, pp. 302-312, 2016.

[67] S. Yoshioka, H. Y. Kim, K. Kasai, "Heat transfer performance and oil behaviour for R744 with PAG oil in air-cooled heat exchanger," in 8th IIR Gustav Lorentzen Conference on Natural Working Fluids, 2008, pp. 389-396.

[68] G. Xia, W. Wang, L. Cheng, D. Ma, "Visualization study on the instabilities of phase-change heat transfer in a flat two-phase closed thermosyphon," Appl. Therm. Eng., vol. 116, pp. 392-405, 2017. 
[69] J. Daguin, K. Arndt, W. Bertl, J. Noite, P. Petagna, H. Postema, P. Tropea, B. Verlaat, "Evaporative $\mathrm{CO}_{2}$ cooling system for the upgrade of the CMS pixel detector at CERN," in 13th InterSociety Conference on Thermal and Thermomechanical Phenomena in Electronic Systems, 30 May-1 June 2012.

\section{Nomenclature}

A cross-sectional area of flow channel, $\mathrm{m}^{2}$;

$C O$ Confinement number, defined by Eq. (1)

$D \quad$ internal tube diameter, $\mathrm{m}$

$F r_{L} \quad$ liquid Froude number $\left[G^{2} /\left(\rho_{L}^{2} g D_{e q}\right)\right]$

$F r_{V, M o r i}$, vapor Froude number $\left[G^{2} /\left(\rho_{v}\left(\rho_{L}-\rho_{v}\right) g D_{e q}\right)\right]$ defined by Mori et al.

$f \quad$ friction factor

$G \quad$ total vapor and liquid two-phase mass flux, $\mathrm{kg} / \mathrm{m}^{2} \mathrm{~s}$

$g$ gravitational acceleration, $9.81 \mathrm{~m} / \mathrm{s}^{2}$

$h$ heat transfer coefficient, $\mathrm{W} / \mathrm{m}^{2} \mathrm{~K}$

$h_{L V} \quad$ latent heat of vaporization, $\mathrm{J} / \mathrm{kg}$

$k$ thermal conductivity, $\mathrm{W} / \mathrm{mK}$

$M \quad$ molecular weight, $\mathrm{kg} / \mathrm{kmol}$

$\operatorname{Pr} \quad$ Prandtl number $\left[c_{p} \mu / k\right]$

$p_{r} \quad$ reduced pressure $\left[p / p_{c r i t}\right]$

$q$ heat flux, $\mathrm{W} / \mathrm{m}^{2}$

Re homogeneous Reynolds number $\left\{\left(G D_{e q} / \mu_{V}\right)\left[x+\rho_{V} / \rho_{L}(1-x)\right]\right\}$

$\operatorname{Re}_{L O}$ Reynolds number considering the total vapor-liquid flow as liquid flow [GDeq $\left./\left(\mu_{L}\right)\right]$

$\operatorname{Re}_{M}$ Reynolds number $\left[G D_{e q} /\left(\mu_{H}\right)\right]$ defined in mist flow

$R e_{V} \quad$ vapor phase Reynolds number $\left[G x D_{e q} /\left(\mu_{V} \varepsilon\right)\right]$

$\operatorname{Re}_{\delta} \quad$ liquid film Reynolds number $\left[4 G(1-x) \delta /\left(\mu_{L}(1-\varepsilon)\right)\right]$

$S \quad$ nucleate boiling suppression factor

$W e_{L}$ liquid Weber number $\left[G^{2} D_{e q} /\left(\rho_{L} \sigma\right)\right] ;\left[\rho_{L} u_{L}^{2} D_{e q} / \sigma\right]$

$W e_{V}$ vapor Weber number $\left[G^{2} D_{e q} /\left(\rho_{\nu} \sigma\right)\right]$

$x \quad$ vapor quality

\section{Greek symbols}

$\delta \quad$ liquid film thickness, $\mathrm{m}$

$\mu \quad$ dynamic viscosity, $\mathrm{Ns} / \mathrm{m}^{2}$

$\theta_{d r y} \quad$ dry angle of tube perimeter, rad

$\theta_{\text {wet }} \quad$ wet angle of the tube perimeter, rad

$\rho$ density, $\mathrm{kg} / \mathrm{m}^{3}$

$\sigma$ surface tension, $\mathrm{N} / \mathrm{m}$

\section{Subscripts}

A annular flow

$B$ bubbly flow

cb convective boiling

crit critical

de dryout completion

$d i$ dryout inception

dry dry

dryout dryout region

$e q$ equivalent

$G \quad$ gas 
$I$ intermittent flow

IA intermittent flow to annular flow transition

$L$ liquid

$L V$ liquid-vapor

$M$ mist flow

$m$ momentum

$n b$ nucleate boiling

sat saturation

tp two phase

$V \quad$ vapour

wet wet perimeter 